\title{
REVERSION OF NEUROMUSCULAR BLOCK WITH SUGAMMADEX IN CHARCOT-MARIE-TOOTH DISEASE: CLINICAL CASE
}

\section{BACKGROUND}

-Charcot-Marie-Tooth disease (CMTd) is an hereditary demyelinating peripheral neuropathy;

-Is characterized by progressive muscular atrophy and sensory-motor abnormalities;

-The major anesthetic consideration is increased sensitivity to non-depolarizing muscle relaxants (NDMR) ${ }^{1}$.

\section{CASE REPORT}

Male patient, 17-year old, ASA III, with CMTd. Sensory-motor deficits more evident in the lower limbs (Fig.1).

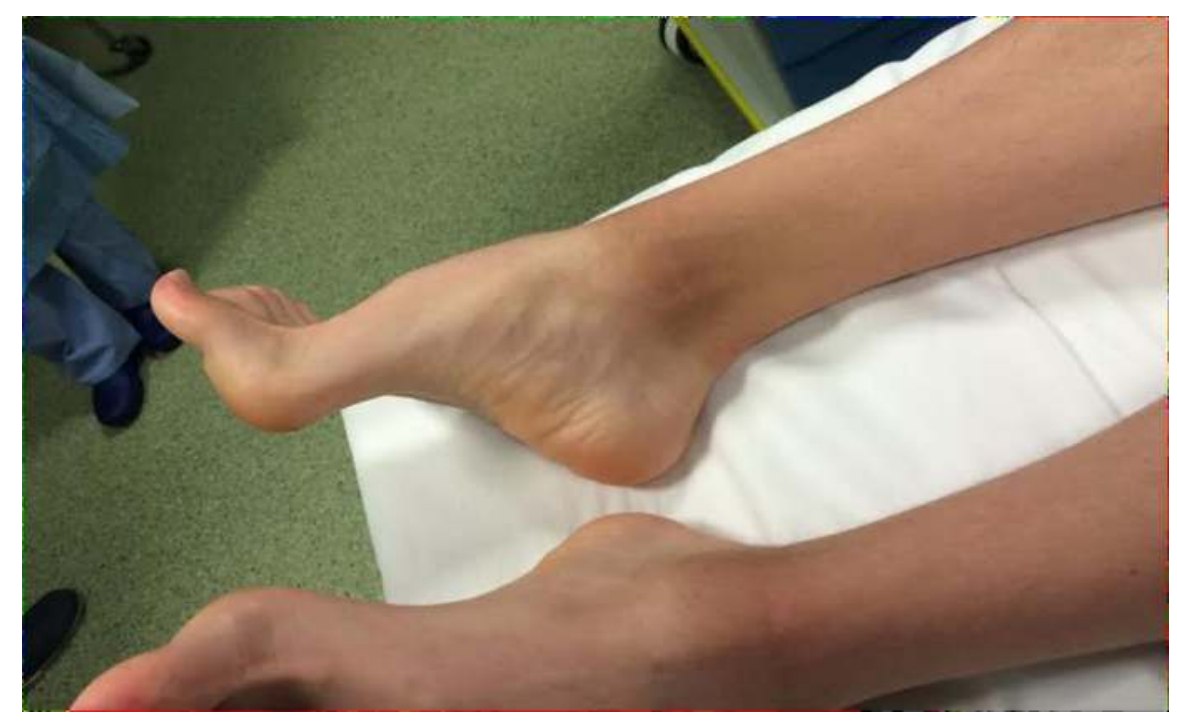

Fig. 1 - Cavus foot of the Patient.

Diagnosis: acute appendicitis.

Proposed surgery: lap. appendectomy.

Anesthetic approach: Balanced General Anesthesia (BGA).

\section{Monitorization}

\begin{tabular}{|c|c|c|}
\hline $\begin{array}{l}\text { Standard ASA } \\
\text { monitorization }\end{array}$ & TOF watch & $\begin{array}{l}\text { Bispectral } \\
\text { Index }^{\mathrm{TM}}\end{array}$ \\
\hline \multicolumn{3}{|c|}{$\begin{array}{l}\text { Neuromuscular relaxation was assessed } \\
\text { through nerve stimulation of the ulnar } \\
\text { nerve with a train-of-four (TOF) stimulus } \\
\text { sequence and subsequent quantification of } \\
\text { the thumb adductor response. }\end{array}$} \\
\hline
\end{tabular}

ANESTHETIC INDUCTION: fentanyl $(2 \mu \mathrm{g} / \mathrm{kg})$ and propofol $(2 \mathrm{mg} / \mathrm{kg})$.

The supramaximal neuromuscular response was measured and recorded using the Organon TOF-Watch SX monitor and rocuronium $(0.6 \mathrm{mg} / \mathrm{kg})$ was administered. Orotracheal intubation was performed 3'30" after NDMR administration, when the 4 responses to TOF disappeared.

\section{ANESTHESIA MAINTENANCE: Desflurane.}

The TOF stimulation was repeated every 5' with a frequency of $2 \mathrm{~Hz}$ and an intensity of $70 \mathrm{~mA}$. During the procedure, neuromuscular blockade monitoring revealed 2 to 3 responses on the TOF-Watch SX monitor.

ANESTHETIC EMERGENCY: For reversion of the residual neuromuscular block, sugammadex $(2 \mathrm{mg} / \mathrm{kg})$ was used and after 2 ' a TOF-ratio of $100 \%$ was obtained (TOF-ratio of $70 \%$ at $1^{\prime} 20$ ", and $90 \%$ after $\left.1{ }^{\prime} 45^{\prime \prime}\right)$.

The surgery lasted 90 minutes without complications.

The postoperative period was uneventful.

The neurological and musculoskeletal examination did not present any new deficits.

\section{DISCUSSION}

-The response to NDMR is variable and its effects may be prolonged. -Due to the chronic demyelination present, the use of succinylcholine can trigger a hyperkalaemic response ${ }^{2}$.

-There are no references to the use of sugammadex in CMTd.

\section{LEARNING POINTS}

-We report the absence of adverse events in the intraoperative and postoperative periods of a laparoscopic appendectomy under BGA using a NDMR in a patient with CMTd.

-We describe, for the first time, the use of sugammadex for the reversal of neuromuscular blockade in a patient with CMTd which occurred successfully and without adverse events. 